\title{
Stimulation of the GnRH Pulse Generator Activity by Continuous Exposure to the Male Pheromones in the Female Goat
}

\author{
Toru ICHIMARU, Yukari TAKEUCHI and Yuji MORI \\ Laboratory of Veterinary Ethology, The University of Tokyo, Yayoi 1-1-1, \\ Bunkyo-ku, Tokyo 113-8657, Japan
}

\begin{abstract}
Male pheromones in ruminant species such as sheep and goats are known to reactivate quiescent ovarian function in seasonally anestrous females. We have previously shown that only a few minutes exposure to the male pheromone can accelerate the GnRH pulse generator activity immediately in the female goat. In this study the effect of $4 \mathrm{~h}$ continuous exposure to the male pheromone on the GnRH pulse generator activity was examined by recording the specific multiple unit acitivity (MUA) from the medial basal hypothalamus. Pooled buck hair was used as the source of male pheromone. Six ovariectomized estradiol-primed does were fitted with a nose-mask for 8 $\mathrm{h}$, and during the latter $4 \mathrm{~h}$ period $2.0 \mathrm{~g}$ of pooled male hair was set in the chamber at the rostral end of the mask. As compared with the period when only an empty mask was put on, the exposure to the male hair resulted in a shortening $(\mathrm{p}<0.05)$ of the interval between the MUA volleys, namely the electrophysiological manifestation of the pulsatile GnRH neurosecretion. This stimulatory effect was observed throughout the time when animals were exposed to the male pheromone. This result demonstrates that the hypothalamic GnRH pulse generator of the recipient female is accelerated as long as the exposure to the male pheromone continues.
\end{abstract}

Key words: Pheromone, Hypothalamus, GnRH pulse generator, Goat.

(J. Reprod. Dev. 45: 243-248, 1999)

$\mathbf{P}$ heromones are chemical signals used to communicate among conspecifics. Primer pheromones are designated to influence recipients' neuroendocrine system, and they subsequently modify various aspects of reproductive function as well as of behavior. One well-known expample of such pheromone-induced gonadal stimulations is the "male effect" [1-3] in which seasonally anovulatory female sheep and goats resume their ovarian cyclicity after being exposed to the male or pheromones that are produced androgen dependently in sexually active males $[4,5]$.

The male effect is mediated by an acceleration of the hypothalamic gonadotropin releasing hor-

Accepted for publication: March 31, 1999

Correspondence: Y. Mori mone $(\mathrm{GnRH})$ pulse generator activity, which then results in increased gonadotropin secretion and consequent follicular development in the quiescent ovary of anestrous females. Previously we investigated the effect of a single application to the male pheromone by means of recording the multiple unit acitivity (MUA) volleys (characteristic increases of the multiple-unit acitivity) from the medial basal hypothalamus of conscious ovariectomized goats [4]. We showed that the application of the male pheromone, which had been accurately timed to the midway between GnRH pulses, actually shortened the inter-pulse interval, i.e., the MUA volley appeared within a few minutes after the pheromone application, which was much earlier than expected.

Using this electrophysiological technique, we could establish a real-time bioassay system for the 
primer pheromone activity with sufficient sensitivity, specificity and reproducibility in the goat [4]. Because the purpose of that study was to examine whether the sample under investigation had pheromonal activity or not, testing materials were simply presented in front of the goat's nostril for a relatively short period ( $<5 \mathrm{~min})$. Therefore it is not yet known how the GnRH pulse generator would respond if the female is exposed to the male pheromone for a longer period, which appears a more likely situation occurring in the natural mating scenes.

In the present study, we therefore extended the duration of pheromone application to $4 \mathrm{~h}$ to test the hypothesis that the increased activity of hypothalamic GnRH pulse generator would be maintained in the female goat when it was subjected to continuous stimulation of the primer pheromone.

\section{Materials and Methods}

\section{Animals and multiple unit activity recording}

Six female Shiba goats were obtained from the closed colony at the experimental station of the University of Tokyo [6]. They were ovariectomized and then implanted with an array of bilateral recording electrodes in the medial basal hypothalamus according to the stereotaxic procedure developed for this goat [7-9]. The method for recording the specific MUA which reflects the function of the hypothalamic GnRH pulse generator has been described in detail in our previous reports $[10,11]$. The MUA showing abrupt increases, which had regular intervals and were exclusively associated with luteinizing hormone (LH) pulses in the peripheral circulation, was considered to be the electrophysiological manifestation of the hypothalamic GnRH pulse generator [11]. During the recording period of MUA, the animals were loosely restrained to the stanchion in the Faraday cage, where they were fed twice a day and provided water ad libitum except for the period when the nose-mask was fitted. The lighting was controlled to be 12L12D or 16L8D (for the longday treatment), and the temperature and relative humidity were kept at $23( \pm 2) \mathrm{C}$ and $40( \pm 5) \%$, respectively, throughout the experiment.

\section{Preparation of the pheromonal substance}

As the source of male pheromone(s), hair sample was collected from the head, cervix and shoulder regions, where the male specific odor was most prominent, of one sexually mature male Shiba goat. The collected hair sample was pooled and stored at $-20 \mathrm{C}$. For each continuous $4 \mathrm{~h}$ application $2.0 \mathrm{~g}$ of hair was used.

The procedure for continuous application was based on the method adopted in previous studies $[3,12-14]$, namely the goat was fitted with a nosemask which was equipped with a chamber to set test substances. For habituation the females were put on empty masks for $4-8 \mathrm{~h}$ for several successive days before they were subjected to the pheromone application.

\section{Experimental design}

In order to mimic the internal and/or external environments in the anestrous season, the ovariectomized goats were subcutaneously implanted with Silastic capsules (i.d. $3 \mathrm{~mm}$, o.d. $5 \mathrm{~mm}$, length 20 $\mathrm{mm}$; Dow Corning, Midland MI., USA) containing crystalline estradiol (Sigma Chemical Co., St Louis MO., USA), and the light condition was changed from 12L12D to $16 \mathrm{~L} 8 \mathrm{D}[15,16]$. The GnRH pulse generator activity was sufficiently suppressed by these treatments, i.e., the interval between MUA volleys was prolonged (over $150 \%$ of the initial baseline levels) and reached a plateau within 3 or 4 days. After that the application of pheromone was conducted.

On Day 0, an empty mask was fitted to the nose of the animal and left for $8 \mathrm{~h}$ from 0900 to 1700 . On the next day (Day 1), the animal was again fitted with the empty mask for the first $4 \mathrm{~h}$ from 0900 to 1300, and then the mask was replaced with the one containing $2.0 \mathrm{~g}$ male goat hair at 1300 , and left for another $4 \mathrm{~h}$ until 1700. To minimize the residual pheromone effects, the air around the upper half of the body was ventilated individually whenever the mask was put on. On Days 2 and 3 the animals were not exposed to the pheromone and the change of MUA volley interval was observed.

The specific MUA was recorded throughout the experiment, and in one representative goat blood samples $(1 \mathrm{ml})$ were collected every 5-10 min via a jugular catheter from 1100 to 1730 on Days 0 and 1 to confirm the synchrony between the MUA vol- 
leys and plasma LH pulses, which had been demonstrated in our previous studies $[4,10,18]$.

\section{Radioimmunoassay}

Plasma concentrations of LH were measured by the double-antibody radioimmunoassay with antiovine LH rabbit serum (YM\#18) and ${ }^{125}$ I-ovine $\mathrm{LH}$ (NIDDK-oLH-I-3) as described elsewhere [17].

The minimal detectable concentration was 0.38 $\mathrm{ng} / \mathrm{ml}$ and the intra-assay coefficiency of variation was $6.8 \%$.

\section{Statistical analysis}

The mean interval between MUA volleys during the exposure to the pheromone (or control period) was calculated for every $2 \mathrm{~h}$ and normalized to the value at the pre-exposure $2 \mathrm{~h}$ period in each of the six individual goats. These standardized data of individual goats were then averaged, and expressed as group means $( \pm$ SEM). The effect of pheromone exposure on the interval was assessed by detecting significant decrease from the basaline level with the paired $t$ test.

\section{Results}

A representative profiles of the MUA volleys and LH pulses at Days 0 and 1 are shown in Fig. 1. The activity of the GnRH pulse generator was accelerated by the male pheromone, and the synchrony between MUA volleys and LH pulses was maintained even during the continuous $4 \mathrm{~h}$ exposure to the male goat hair.

Figure 2 shows successive changes of mean MUA volley intervals of each $2 \mathrm{~h}$ period, which were normalized to the baseline level at 0500-0700 period. When animals were fitted with the empty mask, no significant change was observed in the MUA volley interval. On the other hand, the mean interval between MUA volleys was significantly shortened by exposing the female to the male goat hair, and then it returned to the baseline level within a few hours after the cessation of pheromone exposure.

As shown in Fig. 3, the male pheromone significantly shortened the MUA volley interval throughout the exposure period of Day 1: the mean interval during pheromone exposure (1300-1700) declined to $90.2 \pm 3.7 \%$ of the Day 0 value. No remaining effect was observed on subsequent days.

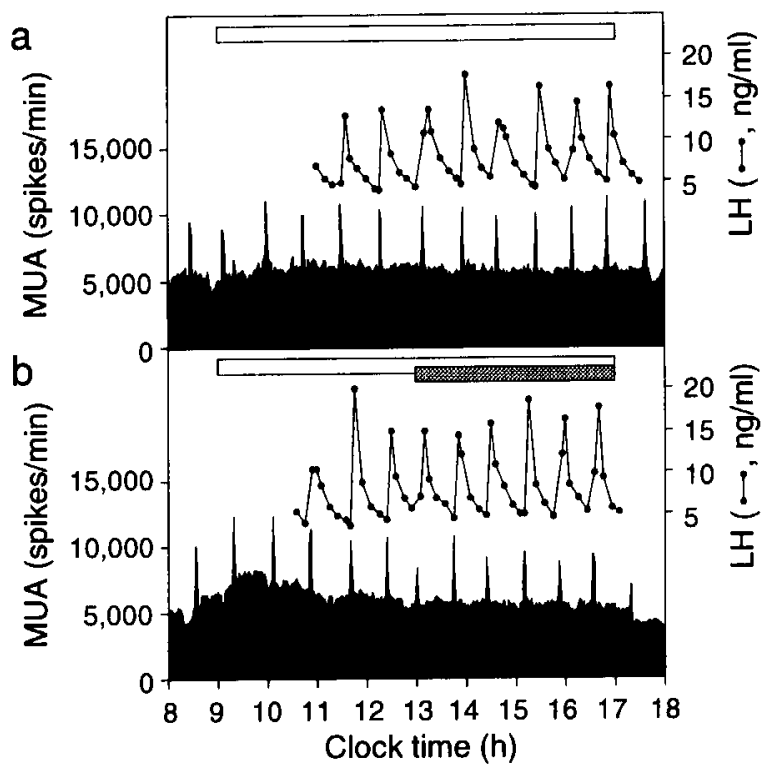

Fig. 1. Synchrony between MUA volleys recorded from the medial basal hypothalamus and LH pulses in the systemic circulation at Day 0 (a) and Day 1 (b) in a representative ovariectomized estradiolprimed goat. The hatched and open bars are the periods during which the goat was put on the nose-mask with and without male goat hair (as the source of the male pheromone), respectively. The MUA volleys were always followed by $\mathrm{LH}$ pulses even when the pulse frequency was altered as a result of the exposure to the pheromone.

\section{Discussion}

In this study, the effect of continuous $4 \mathrm{~h}$ exposure to the pheromone on the activity of the hypothalamic GnRH pulse generator, the center of the reproductive neuroendocrine system, was investigated by monitoring the change of MUA volley intervals. Following the habituation process, the goats showed no signs of distress when fitted with the nose-mask for the continuous pheromone application. The synchrony between MUA volleys and LH pulses was maintained during the experimental period as seen in our previous studies [10, 18-21], even when the pulse frequency was increased by the exposure to the pheromones. No change was observed either in the amplitude or in the basal levels of LH pulses. These findings support the view that, at least as far as the "male effect" is concerned, the pheromone accelerates the hypothalamic GnRH pulse generator activity and then 


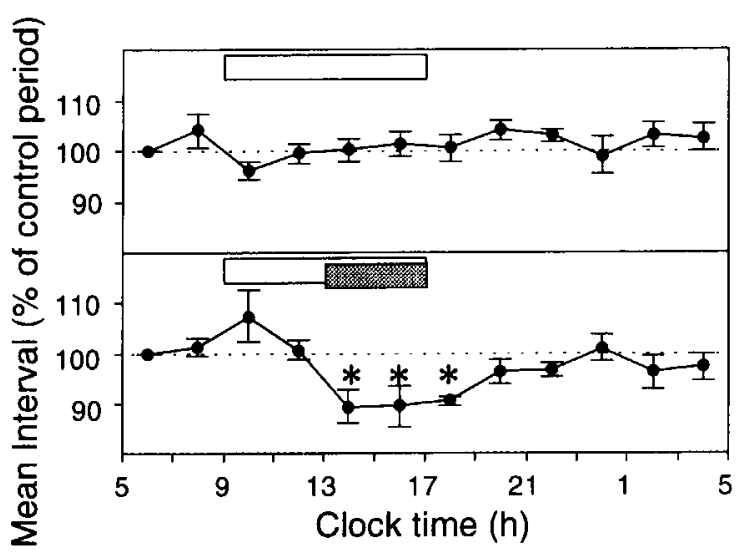

Fig. 2. Sequential changes of MUA volley intervals at Day 0 (a) and Day 1 (b). Mean ( \pm SEM, $n=6$ ) intervals of MUA volleys for $2 \mathrm{~h}$ were normalized to the baseline value at $0500-0700$ of each day, and then the data were averaged for the 6 goats. The asterisks show the differences ( $p<0.05$, paired $t$ test) as compared with the baseline value. The open bar indicates the period when the goat was fitted with the nose-mask (0900-1700) and the hatched bar the period when the male goat hair was contained in the mask (1300-1700).

indirectly stimulates the gonadotropin secretion from the pituitary gland $[3,4]$.

During the continuous exposure to the male pheromone, the interval between MUA volleys decreased significantly, indicating the pheromoneinduced acceleration of the hypothalamic GnRH pulse generator activity. Phenomena that the male pheromone stimulates pulsatile LH secretion were reported in previous studies $[3,4]$. However, it had not been clarified in those reports whether the persistent pheromonal stimulation was necessary to maintain the high frequency of LH pulses. An alternative explanation for this might be that a short term pheromonal stimulation triggered the consequential change of the reproductive neuroendocrine system, and thus increased frequency of LH pulses continue. The latter seems unlikely, however, based on the present observation. In this study the MUA volley interval, which was shortened throughout the pheromone exposure, returned to the former prolonged level soon after the cessation of application. Pheromones are presumed to be accepted by receptors in the vomeronasal organ in mammals [22]. It therefore seems that the central action of the pheromone on the GnRH pulse gen-

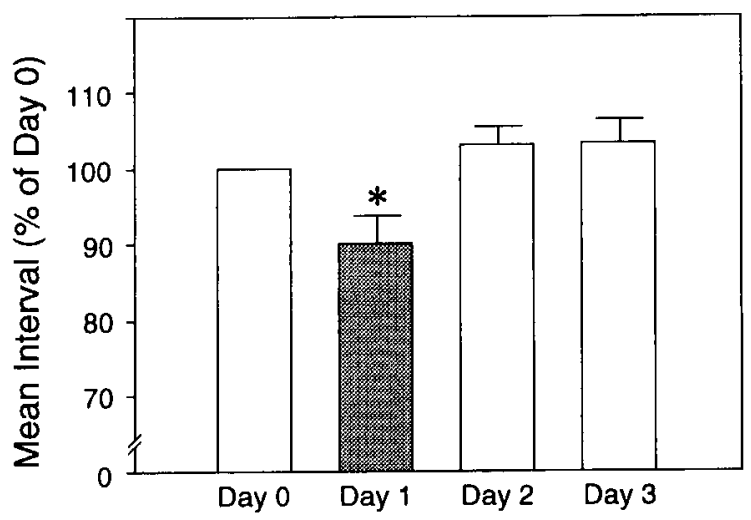

Fig. 3. Mean intervals of MUA volleys observed during the period corresponding to the continuous $4 \mathrm{~h}$ application of male goat hair (1300-1700) at each day between Day 0 and Day 3. Data of each animal were normalized to the Day 0 value (as $100 \%$ ), and then averaged for the 6 animals. The asterisk shows the difference ( $\mathrm{p}<0.05$, paired $t$ test) as compared with the value of Day 0 . The hatched column indicates the day of the continuous $4 \mathrm{~h}$ pheromone application.

erator is exerted only during the period while the pheromone stimulates its receptor systems.

Our previous study with the single application [4] has shown that the pheromonal stimuli instantly induce the MUA volley. As a further extent, the present results have shown that the continuous pheromonal stimulation accelerates the oscillator acitivity of the hypothalamic GnRH pulse generator as long as the stimuli exists. However, the extent of shortening of the MUA volley interval during the continuous application was not comparable to those seen with the single application. Although the reason is unclear, one possible explanation is that only volatile molecules could pass through the mesh of the mask and therefore the stimulation might have been insufficient as compared with the single application where the goat was allowed to not only smell but also taste the male goat hair. Mammalian pheromones were suggested to exhibit their effects more strongly if plural molecules could act cooperatively rather than as a single molecule [23-26]. Pheromones which induce the male effect in sheep, for example, are speculated to be a combination of two or more substances [27]. Although the chemical components of the male goat pheromone are yet to be identified, it appears likely that multiple molecules 
are involved in the biological action of the male pheromone on the GnRH pulse generator.

In conclusion, we have verified the hypothesis that the primer pheromone contained in the male goat hair can stimulate the hypothalamic GnRH pulse generator in the recipient female for relatively long period of time such as $4 \mathrm{~h}$ used in this study.

\section{Acknowledgements}

This work was supported by "Research for the Future" Program, the Japan Society for the Promotion of Science (JSPS-RFTF 97L00904), Grants-in-aid for Scientific Research from the Ministry of Education, Science, Sports and Culture and Grant-in-aid Award (Brain Atlas Programme) from the Ministry of Agriculture, Forestry and Fisheries, Japan.

\section{References}

1. Martin GB, Oldham CM, Cognie Y, Pearce DT. The physiological responses of anovulatory ewes to the introduction of rams - a review. Livest Prod Sci 1986; 15: 219-247.

2. Chemineau P. Possibilities for using bucks to stimulate ovarian and oestrus cycles in anovulatory goats - a review. Livest Prod Sci 1987; 17: 135-147.

3. Claus R, Over R, Denhard M. Effect of male odour on $\mathrm{LH}$ secretion and the induction of ovulation in seasonally anoestrous goats. Anim Reprod Sci 1990; 22: 27-38.

4. Hamada T, Nakajima M, Takeuchi Y, Mori Y. Pheromone-induced stimulation of hypothalamic gonadotropin-releasing hormone pulse generator in ovariectomized, estrogen-primed goats. Neuroendocrinology 1996; 64(4): 313-319.

5. McEwan-Jenkinson D, Blackburn PS, Proudfort R. Seasonal changes in the skin glands of the goat. Br Vet J 1967; 123: 541-549.

6. Kano Y, Sawasaki T, Oyama T. Biological characteristics of miniature 'Shiba' goats. Exp Anim 1977; 26: 239-246.

7. Mori Y, Takeuchi Y, Shimada M, Hayashi S, Hoshino K. Stereotaxic approach to hypothalamic nuclei of the Shiba goat with radiographic monitoring. Jpn J Vet Sci 1990; 52: 339-349.

8. Zuccolilli GO, Hayashi S, Mori Y. Hypothalamic structures of the goat on stereotaxic coordinates. J Vet Med Sci 1995; 57: 459-467.

9. Zuccolilli GO, Mori Y. Cranial and cerebral-ventricular landmarks for accurate stereotaxic approach to hypothalamic nuclei in the goat brain. J Vet Med Sci 1995; 57: 453-457.

10. Mori Y, Tanaka T. Electrophysiological approach to the hypothalamic GnRH pulse generator. J Reprod Fert Suppl 1995; 49: 231-243.

11. Nishihara M, Mori Y, Yoo M-J, Takahashi M. In vivo electrophysiological monitoring of the GnRH pulse generator in rats and goats. In: JE Levine (ed.), Pulsatility in Neuroendocrine Systems. Meth- ods in Neuroscience, vol 20. San Diego: Academic Press; 1994: 114-126.

12. Cohen-Tannoudji J, Locatelli A, Signoret JP. Nonpheromonal stimulation by the male of LH release in the anestrous ewe. Physiol Behav 1986; 36: 921924.

13. Knight TW, Trevit HR, Lynch PR. Effect of boar pheromones, ram's wool and presense of bucks on ovarian activity in anovular ewes early in the breeding season. Anim Reprod Sci 1983; 6: 129-134.

14. Walkden-Brown SW, Restall BJ, Henniawati. The male effect in Australian cashmere goat. 2.Role of olfactory cues from the male. Anim Reprod Sci 1992; 32: 55-67.

15. Karsch FJ, Dierschke DJ, Weick RF, Yamaji T, Hotchkiss J, Knobil E. Positive and negative feedback control by estrogen of luteinizing hormone secretion in the rhesus monkey. Endocrinology 1973; 92: 799-804.

16. Mori Y, Tanaka M, Maeda K, Hoshino K, Kano Y. Photoperiodic modification of negative and positive feedback effects of oestradiol on LH secretion in ovariectomized goats. J Reprod Fert 1987; 80: 523529.

17. Mori Y, Kano Y. Changes in plasma concentrations of $\mathrm{LH}$, progesterone and oestradiol in relation to the occurence of luteolysis, oestrus and time of ovulation in the Shiba goat. J Reprod Fert 1984; 72: 223-230.

18. Mori $\mathbf{Y}$, Nishihara M, Tanaka T, Shimizu T, Yamaguchi M, Takeuchi Y, Hoshino K. Chronic recording of electrophysiological manifestation of the hypothalamic gonadotropin-releasing hormone pulse generator activity in the goat. Neuroendocrinology 1991; 53: 392-395.

19. Ito K, Tanaka T, Mori Y. Opioid peptidergic control of gonadotropin-releasing hormone pulse generator activity in the ovariectomized goat. $\mathrm{Neu}$ roendocrinology 1993; 57: 634-639.

20. Kanai Y, Yamasaki J, Takeuchi Y, Koike N, Fujiyama M, Mori Y. Electrophysiological record- 
ing of hypothalamic GnRH pulse generator activity in castrated male goats. J Reprod Dev 1995; 41: 57-62.

21. Tanaka T, Ozawa T, Hoshino K, Mori Y. Changes in the gonadotropin-releasing hormone pulse generator activity during the estrous cycle in the goat. Neuroendocrinology 1995; 62(6): 553-561.

22. Tirindelli R, Mucignat-Caretta C, Ryba NJ. Molecular aspects of pheromonal communication via the vomeronasal organ of mammals [In Process Citation]. Trends Neurosci 1998; 21: 482-486.

23. Novotny $M$, Jorgenson JW, Carmack M, Wilson SR, Boyes EA, Yamazaki K, Wilson M, Beamer W, Whitten WK. Chemical studies of the primer mouse pheromones. In: D Muller-Schwarze, RM Silverstein (eds.), Chemical Signals in Vertebrates and Aquatic Invertebrates. New York: Plenum
Press; 1980: 377-390.

24. Jemiolo B, Harvey S, Novotny M. Promotion of the Whitten effect in female mice by synthetic analogs of male urinary constituents. Proc Natl Acad Sci USA 1986; 83: 4576-4579.

25. Novotny M, Jemiolo B, Harvey S, Wiesler D, Marchlewska-Koj A. Adrenal-mediated endogenous metabolites inhibit puberty in female mice. Science 1986; 231(4739): 722-725.

26. Melrose DR, Reed HCB, Patterson RLS. Androgen steroids associated with boar odour as an aid to the detection of oestrus in pig artificial insemination. Br vet J 1971; 127: 497-503.

27. Cohen-Tannoudji J, Einhorn J, Signoret JP. Ram sexual pheromone: first approach of chemical identification. Physiol Behav 1994; 56(5): 955-961. 